\title{
Study on Logistics Information of Agricultural Products
}

\author{
Weixia Yang \\ School of business, Xi'an International University \\ Xi'an, China \\ wxyang741117@163.com
}

Keywords: logistics of agricultural products; Logistics information; Countermeasures

\begin{abstract}
With the improvement of the marketization level about agricultural products, the traditional agricultural products supply pattern already could not adapt to the tense supply situation of agricultural products.The agricultural product logistics information is the core of the development of agricultural product logistics. So we must actively promote the agricultural product logistics information in order to makeing the agricultural product logistics further develop. In this paper, on the basis of agricultural products logistics information, combined with the present situation of agricultural logistics informationization development, the author raise the problems existing in the development of agricultural products logistics information, analyze the cause of the problem, and put forward the development countermeasures and policy suggestions of agricultural logistics informationization. It is hoped that this article research can provide some help to the development of agricultural products logistics.
\end{abstract}

\section{Introduction}

At present, with the development of agricultural industrialization, agricultural products logistics has become a bottleneck in the development of agricultural industrialization. With the progress of science and technology, the information technology on the basis of the network technology has been gradually used in the field of agricultural products logistics, which brought new impetus to the development of agricultural products logistics. Through the establishment of agricultural information platform, we will realize logistics information of agricultural products by using the network technology. So on the one hand, we can control logistics cost of agricultural products, through the analysis of the data summary and prediction information system. On the other hand, agricultural products logistics information can combine the agricultural production, processing, circulation and consumption and so on each link organically, which can effectively reduce the cost, and enhance the competitiveness of agricultural products logistics. ${ }^{1}$

\section{Significance of Implementing Agricultural Products Logistics Information}

\section{Connotation of agricultural products logistics.}

Agricultural products logistics information are those which combining both agricultural products logistics and information technology by the application of relevant knowledge of logistics informationization. This means that we utilize modern information technology to process all or part of information prouded in the process of agricultural products logistics, in order to achieving the whole process of the circulation of agricultural products controled, to reduce costs and improve efficiency. Agricultural products logistics informationization is mainly embodied in the agricultural products sales information, transport information and demand for agricultural products.

\section{Significance of Implementing Agricultural Products Logistics Information.}

According to the survey, most sales model in existing markets for agricultural products is still stay in the primary stage of independent traders sell, that accounting for about $77 \%$ of the market. And another mode is the producers directly sell in the market, about $16.7 \%$. This kind sales model

${ }^{1}$ Fund Project: Fund project of Xi'an social science planning (14IN04) ; Project of special scientific research plan in education department of Shaanxi province (14JK2100) 
make market information and logistics information not transparent and make agricultural market demand information, supply information and logistics information asymmetrical, which eventually lead to low overall efficiency of agricultural products logistics in our country. If we accelerate the construction of our country agricultural products logistics information system, it will can largely improve profitability of the whole supply chain of agricultural products, at the same time also can reduce the logistics cost of agricultural products, improve the production efficiency, and increase farmers income. Ultimately, it can enhance the market competitiveness of agricultural products in China, and lay the solid foundation for the further development of national economy.

\section{Problems Existing in the Agricultural Products Logistics Information}

\section{The Problem in Objective Aspect.}

1) Information asymmetry

Asymmetric information is all-important sign of the backward agricultural products logistics information, it grievously obstructed circulation of agricultural products seriously. Take, for example kiwi fruit of zhouzhi county in Shanxi Province, kiwis the great majority of xi 'an spending are from zhouzhi county. But on the one hand, as a producer, farmers couldn't find a good channel to sell in bulk in kiwi fruit mature, on the other hand businesses as a kiwi fruit processing and sales of terminal are difficult to acquire to eligible quality kiwi fruit. The information asymmetry seriously hindered the circulation of agricultural products, it make agricultural products sales missed the best time. In 2011, for example, the zhouzhi county building in the town of guangtai, because kiwi businesses are difficult to find the right sales channels, leading nearly 700000 jins kiwi fruit unmarketable, direct economic loss of 2.8 million yuan, it caused huge economic losses to local farmers.

\section{2) Information distortion}

Because most of farmers are poor and undereducated, the way to get the information is hearsay, more information is getted by second-hand accounts, and these information is error easily. We remember the phenomenon of "vegetable base hurt as if it were yesterday. After investigation, we found that agricultural markets are frequent fluctuations in the price of unsalable and the reason is that agricultural products production and sales of intermediate links, farmers docking with citizens that requires two or three layers "middleman". In addition, vegetable unmarketable condition occurring, it is because that almost all farmers suit planting, farmers see what first year price is high, in the coming year they will plant what kind of, rather than according market demand. Therefore, there is no accurate information will enable farmers to make the wrong decision, ultimately lead to out of stock or unsalable.

\section{3) Information lag}

The mode by which agricultural products terminal sales information transmitted is backward and the speed is slow, such as oral transfer information between farmers, traders, it will waste too much time in the circulation process, and often leads to produce missed the best opportunity to enter the market, eventually led to the farmers forced to at a low price to get rid of it.

\section{The Problem in Subjective Aspect.}

1) Trade units participation of informatization is of low level of motive

Influenced by traditional ways of production and management, the ideas of " cash on delivery" is deep-seated in many buyers and sellers. In addition,Farmers living scattered, and is in poor communication channels, many information about agricultural products is difficult to collect and transfer, agricultural information network can effectively solve this problem, but the main problem is that the fault appears online in the township and village, the farmers access to information at very high cost . And because the low degree of culture of most of the farmers, it make them lack of ability to respond to new technology and market analysis ability and choose ability. Thus it cause the blindness of farmers' production and circulation of agricultural products.

2) The government on the importance for agricultural products logistics information is not enough 
An important reason of Influencing the prevalence rate of rural network is the lack of understanding of logistics information, so information consciousness of farmers do not keep pace with the development of modern agriculture. Government on the importance for agricultural products logistics information is not enough, and it donot a propaganda and the correct guidance. These eventually led to the farmers lack ability of analysis the emerging technology and the ability to adapt it , not in a timely manner to realize the importance of logistics information technology.

\section{Reason of for the Problems Existed In Agricultural Products Logistics Information}

\section{The lack of infrastructure for agricultural products logistics information.}

First of all, most farmers think that network cost and computer hardware cost is relatively high, they can't afford or don't want to bear these costs. Second, the Internet users and website of agriculture are mainly distributed in urban areas, the real rural users are rare. Moreover, the web site that attach agricultural information as the main content is very few,really useful agricultural information content is very poor. In addition, agricultural products logistics infrastructure such as construction transportation, storage and transportation and warehousing facilities is not perfect.

Distribution channels for agricultural products logistics information is single.

Firstly, the development of integrated network platform is not mature, especially effective network information communication channels between the villages and towns is very lack. For example, the channels of releasing logistics information in $\mathrm{Xi}$ 'an surrounding agricultural departments at the grass-roots is very little, the media do not effective communicate and cooperate in transmission and releasing the agricultural logistics information, these lead to information be insufficient. Second, service electronic level of the xi 'an agriculture administrative department is low, they are unable to provide more effective regulatory agencies and the public network services. In addition, the government do not establish a sound market economic order in terms of market regulation of products and production materials.

Factors Lack of specialized personnel in agricultural products logistics information.

Talent is the important bottleneck that restrict the development of the agricultural products logistics informationization. It is because that agricultural products logistics information construction is a comprehensive strong, with high specialization degree requirements work. that affect the work efficiency such as personnel operation not skilled, wrong operation, and simple fault cannot be ruled out.

\section{Countermeasures to promote the development of agricultural products logistics information}

\section{Macro countermeasures.}

1) The government should strengthen the macroeconomic regulation and control function in agricultural products logistics information

Construction of agricultural products logistics information is a complex systematic project, It must arouse the enthusiasm of multiple and coordinated. The government should actively play a role of macroeconomic regulation and control in this respect, and formulate feasible long-term planning of construction of logistics informationization. Without really viable long term solution, it may cause the parties individually, so as to slow the process of construction of logistics informationization. Therefore, the government department should formulate a scientific and reasonable long-term planning, strengthen the management of the agricultural products market, improve the agricultural product market system, and improve the wholesale market for agricultural products. The government will vigorously support local agricultural information network construction, and treating the agricultural products logistics information construction work as a strategic task to take seriously. 
2) Strengthen the demonstration and guidance of informationization in the field of logistics

Information is the core of modern logistics, information technology is widely used in the field of logistics that is necessary in the development of the modern logistics. Authorities should set up some more demonstration base in the logistics information logistics informationization for enterprises, it may drive and promote the construction of the agricultural products logistics information. Enterprises and farmers is the main end user of information services, so we must enhance their consciousness of acquiring and using information, through various means to stimulate farmers' desire and ability to use of agricultural information, and make the agricultural products logistics information better service to farmers.

3) Intensify the building of logistics information infrastructure of agricultural products

To realize agricultural products logistics informatization is the inevitable development trend of the development of agricultural products logistics industry. To realize the agricultural products logistics information, it is necessary to pay attention to the construction of agricultural products logistics information infrastructure. For example,to improve network coverage and the basic construction, equipped with advanced information terminal equipment. At the same time, we should strengthen software research about agricultural products logistics application, and develope the whole process of system management software that include agricultural production, processing, packing, transportation, storage, sales, etc. So it may produce the entire management, improve the level of logistics information management.

\section{Micro countermeasures.}

1) Increase the degree of farmers organization

It is the basic way to save the cost of logistics of agricultural products, improve the efficiency of logistics and ensure the information flow that we improve farmer's organization degree. For example, we may appropriate concentrate the dispersed land and improve the management scale of individual families,or improve agricultural production scale. So we may reduce the production cost of agricultural products, improve production efficiency, and concentratethe agricultural products. Such as again, we may change the traditional farming mode, advocates and develope the pattern of agricultural industrialization management,that is we may forme "production base + farmer" forms of industrial organization pattern in order to drive farmers to enter the market by the leading companies concentrate on dispersed farmers. This pattern makes the agricultural products logistics information channel more open, and it is an important channel to promote the development of agricultural products logistics information construction.

2) Vigorously develop professionals of agricultural products logistics information

We need a number of highly qualified personnel of information management during the construction of logistics information. Firstly, as a powerful rear to training talents, colleges and universities should actively bring up a large number of professional talent who has agricultural knowledge, is good at information technology, and is the master of logistics management. These may relieve the shortage of agricultural products logistics informationization talented person. Secondly, we may through a variety of ways of training, to speed up the build talent team who is a root to the modernization of rural farmers, service information. Improve the management of cadres at all levels.for exmple,we should popular agricultural products logistics information education by A variety of publicize and promote logistics knowledge.

\section{Summary}

Agricultural products logistics informationization is particularly important in the development of modern logistics of agricultural products, and improving the market competitiveness of agricultural products logistics information is also the requirement of times development. We should vigorously promote agricultural products logistics information process, widespreadly adopt modern information technology, and improve the level of the development and utilization of information resources. Of course, the of construction agricultural products logistics information also is not achieved overnight, but it is a long and complicated process, iit needs the government, enterprises 
and individuals of various common efforts and support. In this way, The development of agricultural products logistics informationization is meeting a new step.

\section{References}

[1] Cai RongFei, "Study of the problem of agricultural products logistics information in xinjiang”, Cooperation Economic and Technological, no. 4, pp.57-59, 2011

[2] Wang ZhongJun,“Brief on the experience of foreign agricultural products logistics”, Logistics Engineering and Management, No.2, Pp.34-35, 2011.

[3] Wu Hui Jie,“Modern Logistics Enterprisescustomer Relationship Management ”, Enterprise , no. 5, pp.245-247, 2011

[4] Elise Golan, Barry Krissoff, Linda Calvinand Kenneth Nelson. Traceability in the USA food supply: Economic Theory and Industry Studies[J].Agricultural Economic Report.2004,(03)

[5] Meng FanSheng "“the Third Party Logistics Enterprise Customer Relationship Management”, Operation and Management, no. 6, pp.63-65, 2011

[6] Zhao Yang, "the third Party Logistics Enterprise Customer Relationship Management ", Operation and Management ,no. 8, pp.57-59, 2010. 